\title{
Persepsi Pengunjung Domestik Terhadap Wisata Entertainment di Daya Tarik Wisata Kawasan Luar Pura Uluwatu
}

Kesya Marcella Tjampan a,1, Saptono Nugroho a, 2

1 kmtjampan17@gmail.com, ${ }^{2}$ saptono_nugroho@unud.ac.id

a Program Studi Sarjana Destinasi Pariwisata, Fakultas Pariwisata, Universitas Udayana, Jl. Dr. R. Goris, Denpasar, Bali 80232 Indonesia

\begin{abstract}
The strategy forming tourist attraction to attract repeating guest is by developing entertainment tourism which offers sense of pleasure, satisfaction, and valuable experience. Uluwatu Kecak Fire Dance in Outer Area Uluwatu Temple was recognized as the most famous entertainment forms by domestic visitors. This aim of study is to identifying characteristics and measuring perception of domestic visitors to Uluwatu Kecak Fire Dance based on seven operational dimensions of entertainment tourism (Learning, Enjoyment, Escape, Refreshment, Novelty, Involvement, and Local Culture). The research used qualitative method with data collection techniques are questionnaire (number of samples were 65 respondents) and literature study. The data analysis technique used descriptive statistical analysis with continuum lines. The results showed that the perception of 65 domestic visitors for entertainment tourism in Uluwatu Temple were strongly agreed on Learning (277.5) and Enjoyment (285). While perception that were agreed are Escape (227), Refreshment (248.5), Novelty (259.25), Involvement (266), and Local Culture (272.33). In determining the dominant indicators of each dimension of entertainment tourism, the author uses the highest frequency capacity value. The three dimensions with highest average value are Enjoyment (285), Learning (277.5), and Local Culture (272.33). The administrator Outer Area Uluwatu Temple emphasize strategies that can maintain the three dimensions of entertainment tourism that have a dominant value, which is the Enjoyment dimension, Learning dimension, and the Local Culture dimension.
\end{abstract}

Keyword: Visitor Perception, Socio-demographic Characteristics, Entertainment Tourism, Domestic Visitors

\section{PENDAHULUAN}

Atraksi adalah salah satu komponen produk pariwisata yang wajib ada di suatu DTW sehingga diperlukan adanya upaya pengemasan atraksi wisata yang menarik dan atraktif dimana disesuaikan dengan minat dan selera wisatawan agar segala kebutuhan selama di DTW terpenuhi (Cooper dkk., 1993) dalam Suwena dan Widyatmaja, 2017:103).

Salah satu strategi pengemasan atraksi wisata yang mampu menghasilkan kunjungan wisatawan secara berulang atau repeater guest yaitu dengan memasukkan unsur hiburan atau entertainment ke dalam atraksi wisata, kemudian dikembangkan menjadi wisata entertainment (pariwisata hiburan). Secara esensial, unsur entertainment memberikan tiga manfaat penting bagi kehidupan manusia diantaranya alat menjaring jumlah wisatawan secara masif, memenuhi skala kesenangan, dan memberikan pengalaman berharga (Adeboye, 2012).

Wisata entertainment sebagai kegiatan wisata bernuansa ringan, menawarkan kesenangan, tidak menuntut wisatawan untuk melakukan suatu kegiatan tertentu, dan tidak memerlukan apresiasi yang tinggi terhadap produk hiburan yang ditawarkan. Wisata entertainment dapat diidentifikasi sebagai: bar, club dan restoran, taman bermain dan waterpark, teater, bioskop, live performances, stadion olahraga, museum, festival, pagelaran musik/ konser, dan atraksi entertainment lainnya (Hughes, 2000)

Wisata entertainment di Indonesia yang menarik kunjungan wisatawan adalah live performance Kecak Fire Dace Uluwatu yang terletak di Daya Tarik Wisata (DTW) Kawasan Luar Pura Uluwatu. Hiburan berupa atraksi budaya ini digelar pada sore hari (18.00-19.00 Wita) sambil menikmati sunset dan cultural landscape Pura Uluwatu yang sangat indah (Anom, dkk., 2020).

Atraksi budaya Kecak Fire Dance Uluwatu dijadikan sebagai salah satu preferensi dari lima besar DTW yang paling diminati dan wajib dikunjungi pengunjung domestik untuk saat berkunjung ke Bali (Dinas Pariwisata Provinsi Bali, 2018). Pengunjung domestik yang menyaksikan Kecak Fire Dance Uluwatu memiliki penilaian atau persepsi yang berbeda tergantung dari karakteristik sosio-demografis masing-masing., Seperti usia, gender, tingkat pendidikan, pekerjaan, tipe keluarga dan jumlah anggota keluarga yang ikut dalam perjalanan wisata tersebut (Smith, 1986 dalam Nurhidayah dan Musadad, 2017). Penilaian atau persepsi wisatawan dibutuhkan untuk menilai apakah DTW tersebut sudah memenuhi kebutuhankebutuhan pengunjung dan mengevaluasi hal-hal yang wajib diperbaiki, sehingga pihak pengelola mampu memantau pergerakan pengunjung domestik di DTW Kawasan Luar Pura Uluwatu sekaligus merumuskan kebijakan/ srategi yang 
tepat terhadap pengelolaan Kecak Fire Dance Uluwatu di masa yang akan datang (Setiawan dkk., 2016)

Telaah hasil penelitian sebelumnya, pertama dilakukan oleh Jian Ming Luo, Chi Fung Lam, dan Daisy X. F. Fan (2018) dengan judul "The Development of Measurement Scale for Entertainment Tourism Experience: A Case Study In Macau". Penelitian ini bertujuan untuk mengukur tingkat pengalaman pengunjung terhadap wisata entertainment dari perspektif pengunjung di Kota Makau, Republik Rakyat Tiongkok denan menggunakan tujuh dimesi operasional wisata entertainment. Hasil yang didapatkan dalam penelitian adalah nilai maksimum persepsi pengunjung terdapat pada dimensi Enjoyment (avg=4.06) karena berhubungan dengan pemenuhan kesenangan, dimensi Local culture (avg=3.98) karena pengunjung perlu berinteraksi dengan masyarakat lokal, and dimensi Learning (avg=3.90) karena pengunjung berbagi fasilitas entertainment dengan masyarakat lokal.

Penelitian kedua dilakukan oleh Nuraini Kintan Utami (2019) dengan judul "Pengalaman Pengunjung Di Asia Afrika Festival 2019”. Penelitian ini bertujuan untuk mengukur tingkat pengalaman pengunjung Asia Afrika Festival 2019 di Kota Bandung berbasis tiga dimensi yaitu program and service, self-experience, dan accessibility. Hasil yang didapatkan dalam penelitian ini adalah: 1) dimensi program \& service berkategori sangat setuju atau sangat baik (rata-rata nilai 213,08); 2) dimensi selfexperience berkategori sangat setuju atau sangat baik (rata-rata nilai 216,33); dan 3) dimensi accessibility berkategori sangat setuju atau sangat baik (rata-rata nilai 229,33).

Penelitian ketiga dilakukan oleh Said Keliwar dan Anton Nurcahyo (2015) dengan judul penelitian "Motivasi Dan Persepsi Pengunjung Terhadap Obyek Wisata Desa Budaya Pampang Di Samarinda". Penelitian ini bertujuan untuk mengidentifikasi karakteristik dan tingkat persepsi pengunjung terhadap pengelolaan DTW, fasilitas umum dan fasilitas pariwisata, aksesibilitas pariwisata di Desa Budaya Pampang, Kota Samarinda. Hasil yang didapatkan dalam penelitian ini adalah 1) Berjenis kelamin laki-laki (58.9\%); 2) Berusia antara 21-30 tahun (66.1\%); 3) Tingkat pendidikan terakhir SMA/SMK (51.8\%); 4) Bekerja sabagi wiraswasta (35.7\%); 5) dan penghasilan lebih dari Rp.3.000.000 (51.8\%). Sedangkan persepsi pengunjung terhadap Desa Budaya Pampang dibagi berdasarkan tiga kategori penilaian, yaitu: 1) Sangat Puas (variabel keunikan daya tarik Desa Pampang); 2) Puas (variabel keunikan cinderamata dan penataan toko cinderamata, kenyamanan dan keamanan); serta 3) Kurang Puas (variabel transportasi umum, sarana jalan, fasilitas dan kebersihan pengunjung).

Penelitian ini menggunakan empat konsep untuk menganalisis data yang diperoleh. Ada pun konsep tersebut, yaitu Wisata Entertainment, Karakteristik Sosio-demografis (Tourist Descriptor), Persepsi Pengunjung, dan Pengunjung Domestik.

\section{Wisata Entertainment}

Swarbrooke dan kawan-kawan (2003:5 dalam Adeboye, 2012:7) menjabarkan wisata entertaiment digambarkan sebagai hal yang bersifat bersifat bebas; memberikan rasa kesenangan, ekspresif, dan kepuasan; serta berlangsung di tempat dan waktu yang jauh dari jangkauan bisnis maupun keluarga. Xu (2010 dalam Luo dan Lam, 2017:4) menambahkan wisata entertainment juga disusun secara objektif untuk memberikan pengalaman yang berkesan dan tidak terlupakan. Luo dan kawan-kawan (2018:4-7) membagi tujuh dimensi operasional dari wisata entertainment yaitu Learning Enjoyment, Escape, Refreshment, Novelty, Involvement, dan Local Culture.

\section{Learning}

Learning atau "Belajar" merupakan elemen wisata entertainment yang didapatkan pengunjung setelah mempelajari informasi dan keterampilan baru yang ada di destinasi entertainment (Pearce, 2005). Dimensi Learning mampu tercapai apabila memenuhi indikator-indikator sebagai berikut:

a. Pengunjung berusaha memperluas pemahaman tentang wisata entertainment.

b. Pengunjung memperoleh informasi dan pengetahuan tentang wisata entertainment.

c. Pengunjung mempelajari banyak hal tentang wisata entertainment.

d. Pengunjung belajar budaya baru.

2. Enjoyment

Enjoyment atau "Kenikmatan" merupakan dimensi wisata entertainment yang didapatkan pengunjung setelah melakukan kegiatan yang memberikan kesenangan secara maksmimal (Davis dan kawan-kawan, 1992). Dimensi Enjoyment mampu tercapai apabila memenuhi indikatorindikator sebagai berikut:

a. Pengunjung bersenang-senang.

b. Pegunjung menikmati momen keberadaannya selama menyaksikan atraksi wisata entertainment.

c. Pengunjung merasa senang saat melakukan perjalanan menuju ke lokasi atau DTW wisata entertainment.

d. Bentuk wisata entertainment yang ditampilkan memotivasi pengunjung untuk melakukan perjalanan menuju DTW tersebut. 


\section{Escape}

Escape atau "Pelarian" merupakan dimensi wisata entertainment yang didapatkan pengunjung ketika merasa jenuh dan berkeinginan 'melarikan diri' dari kehidupan sehari-hari (Pearce, 2005). Dimensi Escape mampu tercapai apabila pengalaman pengunjung memenuhi indikatorindikator sebagai berikut:

a. Pengunjung merasakan seperti berada di dimensi lain.

b. Pengunjung merasakan lepas dari segala urusan di kehidupan sehari-hari.

c. Pengunjung terlalu menikmati atraksi wisata entertainment yang ditawarkan destinasi sehingga melupakan hal-hal di sekelilingnya.

d. Pengunjung melakukan sesuatu yang bermakna.

\section{Refreshment}

Refreshment atau "Penyegaran" merupakan dimensi wisata entertainment yang didapatkan pengunjung ketika terjadi pembalikan sementara situasi dari kegiatan sehari-hari menuju situasi tanpa pekerjaan, tanpa perawatan, dan tanpa penghematan Cohen (1979). Dimensi Refreshment mampu tercapai apabila memenuhi indikatorindikator sebagai berikut:

a. Pengunjung merasa terbebaskan secara psikis (mental) ketika menikmati atraksi wisata entertainment.

b. Pengunjung merasa disegarkan kembali.

\section{Novelty}

Novelty atay "Kebaruan" merupakan dimensi wisata entertainment yang didapatkan pengunjung ketika secara psikologis merasakan pengalaman baru yang didapatkan dengan mengeksplorasi destinasi wisata dengan budaya dan gaya hidup yang berbeda dari daerah asal mereka (Pearce, 1987). Dimensi Novelty mampu tercapai apabila memenuhi indikator-indikator sebagai berikut:

a. Pengunjung beranggapan menyaksikan atraksi wisata entertainment adalah pengalaman sekali seumur hidup.

b. Pengunjung merasa atraksi wisata entertainment itu unik.

c. Pengunjung merasakan pengalaman yang berbeda dari sebelumnya saat menyaksikan atraksi wisata entertainment.

d. Pengunjung mengalami sesuatu yang baru.

\section{Involvement}

Involvement atau "Keterlibatan" merupakan dimensi wisata entertainment yang didapatkan pengunjung dalam tingkat identifikasi yang dicapai melalui kenikmatan dan ekspresi diri ketika individu berpartisipasi dalam kegiatan terkait (Selin dan Howard, 1988). Dimensi Involvement mampu tercapai apabila memenuhi indikator-indikator sebagai berikut: a. Pengunjung mengunjungi DTW wisata entertainment sebagai destinasi yang benarbenar ingin dikunjungi.

b. Pengunjung menikmati pertunjukan yang ingin disaksikan selama di DTW wisata entertainment.

c. Pengunjung tertarik pada atraksi wisata entertainment yang disediakan di DTW.

\section{Local Culture}

Local culture atau "Budaya Lokal" merupakan dimensi wisata entertainment yang didapatkan pengunjung ketika memiliki pemahaman terhadap budaya lokal melalui interaksi dengan penduduk setempat (Kim, 2014 dalam Qi dan kawan-kawan, 2013). Dimensi Local Culture mampu tercapai memenuhi indikator-indikator sebagai berikut:

a. Pengunjung memiliki kesan yang baik tentang masyarakat lokal.

b. Pengunjung mengalami ikatan yang erat dengan budaya lokal.

c. Pengunjung merasakan keramah-tamahan masyarakat lokal di DTW.

\section{Karakteristik Sosio-demografis Descriptor)}

Seaton dan Bennet (1996) mengemukakan bahwa karakteristik wisatawan (tourist descriptor) memfokuskan pada pengelompokkan wisatawan berdasarkan karakteristik sosio-demografis, karakteristik geografis, dan karakteristik psikografis. Karakteristik sosio-demografis merupakan klafisikasi karakteristik yang berhubungan dengan demografi atau kependudukan. Smith (1986) memaparkan indikator-indikator karakteristik sosio-demografis sebagai berikut: Jenis Kelamin, Usia, Tingkat Pendidikan, Pekerjaan, Jumlah Anggota Keluarga dan Komposisinya, dan Tipe Keluarga.

\section{Persepsi Pengunjung}

Keliwar dan Nurcahyo (2015:16) mengemukakan persepsi adalah kesan individu secara inderawi terhadap sesuatu yang pernah atau sedang dialami baik secara fisik (tangible) maupun non-fisik (intangible). Persepsi wisatawan adalah kesan yang diwujudkan dalam bentuk interpretasi dan sikap terhadap daya tarik pariwisata, fasilitas pariwisata, fasilitas umum, informasi pariwisata serta pelayanan yang diberikan kepada wisatawan selama berada di DTW tersebut.

\section{Pengunjung Domestik}

Definisi pengunjung domestik dalam International Recommendations of Tourism Statistics 2008 oleh UNWTO adalah sebagai berikut:

Poin 2.9: "Pengunjung (visitor) adalah seorang pelancong (traveller) yang melakukan perjalanan ke tujuan utama di luar lingkungan biasanya, selama 
kurang dari setahun, untuk tujuan utama apa pun (bisnis, liburan, atau keperluan pribadi lainnya) selain untuk dipekerjakan oleh entitas penduduk di negara tersebut atau tempat yang dikunjungi."

Poin 2.10: "Pelancong domestik (melakukan perjalanan wisata dalam negeri) disebut dengan pengunjung domestik."

Pengunjung domestik dijadikan parameter keberhasilan kepariwisataan nasional dikarenakan tingkat aktivitas pariwisata yang dilakukan tergolong progresif seiring dengan perkembangan sektor transportasi yang memberikan kemudahan aksesibilitas dan pergeseran motif berwisata pengunjung dometik cenderung mengarah pada pemenuhan kebutuhan rekreasi sesuai life style atau gaya hidup (https://disparda.baliprov.go.id/).

\section{METODE PENELITIAN}

Penelitian ini berlokasi di Daya Tarik Wisata (DTW) Kawasan Luar Pura Uluwatu, Desa Adat Pecatu, Kecamatan Kuta Selatan, Kabupaten Badung, Provinsi Bali yang dilakukan bulan Februari 2020 sampai bulan Juni 2020. Ada pun ruang lingkup pembahasan dalam penelitian ini terbagi menjadi dua, yakni: 1) Karakteristik Pengunjung Domestik yang Menyaksikan Wisata Entertainment di DTW Kawasan Luar Pura Uluwatu (jenis kelamin, usia, tingkat pendidikan, pekerjaan, jumlah anggota keluarga dan komposisinya, dan tipe keluarga); dan 2) Persepsi Pengunjung Domestik terhadap Wisata Entertainment di DTW Kawasan Luar Pura Uluwatu, berdasarkan sub-variabel tujuh dimensi operasional wisata entertainment berserta indikatornya: Learning (4), Enjoyment (4), Escape (4), Refreshment (2), Novelty (4), Involvement (3), dan Local Culture (3). Penelitian ini menggunakan metode deskriptif kualitatif untuk medeskripsikan data kuantitatif yang diolah atau dianalisis dengan menggunakan teknik perhitungan statistik (Siregar, 2013:17).

Penelitian menganut paradigma kuantitatif, bersifat deduktif dengan menggunakan metode dan analisis data kuantitatif (Anom, dkk., 2019). Untuk memperoleh data, penelitian ini menggunakan dua sumber, yaitu data primer yang diperoleh dari hasil kuisioner penelitian yang dibagikan secara online (Google Form) dan data sekunder yang diperoleh dari pemahaman literatur seperti buku, skripsi, jurnal ilmiah, dan media online. Data penelitian diperoleh melalui kuisioner tertutup dengan pengukuran Skala Likert dan studi kepustakaan (Siregar, 2013:21; Praing dan kawan-kawan, 2019:29). Indikator variabel (Ruang Lingkup Penelitian) yang diukur menggunakan skala likert diuraikan dalam bentuk penilaian yang mempunyai skor jawaban 1-5 sebagai berikut:

$$
\text { SS : Sangat Setuju } \quad=5
$$

$\begin{array}{lll}\text { S } & \text { : Setuju } & =4 \\ \text { KS } & \text { : Kurang Setuju } & =3 \\ \text { TS } & \text { : Tidak Setuju } & =2 \\ \text { STS } & \text { : Sangat Tidak Setuju } & =1\end{array}$

Pengambilan sampel dalam penelitian ini menggunakan teknik purposive sampling. Penarikan sampel berdasarkan pada kriteriakriteria tertentu untuk memenuhi data yang diharapkan oleh peneliti sehingga responden penelitian merupakan seluruh populasi pengunjung domestik yang menyaksikan Kecak Fire Dance Uluwatu (Siregar, 2013:33). Penentuan jumlah sampel representatif dari populasi pengunjung domestik di DTW Kawasan Luar Pura Uluwatu selama masa jangka waktu penelitian tidak diketahui 0 dihitung menggunakan rumus menurut Hair (https://www.researchgate.net; Hair, 1995 dalam etheses.uin-malang.ac.id) tergantung pada jumlah indikator penelitian kemudian dikalikan 5 sampai 10. Jumlah sampel dalam penelitian ini adalah:

$$
\begin{aligned}
\text { Sampel } & =\text { Jumlah Indikator (RLP) } \times 5 \\
& =13 \times 5 \\
& =65 \text { responden }
\end{aligned}
$$

Untuk menganalisis data digunakan dua teknik, yaitu statistik deskriptif dimana menggunakan statistik untuk mendeskripsikan data dan garis kontinum yang menentukan skala rentang nilai atau range (R) serta menentukan posisi setiap jawaban kuisioner (Muhson, 2006:1-2; Utami, 2019:25). Cara menentukan garis kontnum menggunakan perhitungan sebagai berikut:

A. Menentukan Jumlah Skor Tertinggi dan Terendah

\begin{tabular}{lcc}
\hline Kategori Nilai & $\begin{array}{c}\text { Perhitungan Nilai } \\
\text { (Skor Tertinggi } \\
\text { Total Responden) }\end{array}$ & Total Nilai \\
\hline Nilai & $5 \times 65$ & 325 \\
Maksimum & $1 \times 65$ & 65 \\
\hline Nilai Minimum &
\end{tabular}

B. Menentukan skala rentang nilai atau range (R)

$$
\begin{aligned}
& \mathrm{R}=\text { Nilai Maksimum }- \text { Nilai Minimum / Kelas Interval } \\
& \mathrm{R}=325-65 / 5 \\
& \mathrm{R}=52
\end{aligned}
$$

\begin{tabular}{cl}
\hline $\begin{array}{c}\text { Skala Rentang } \\
(\text { Range }) \text { Nilai }\end{array}$ & \multicolumn{1}{c}{ Keterangan } \\
\hline $65-117$ & Sangat Tidak Setuju \\
\hline $117-169$ & Tidak Setuju \\
\hline $169-221$ & Netral (Biasa Saja) \\
\hline $221-273$ & Setuju \\
\hline $273-325$ & Sangat Setuju \\
\hline
\end{tabular}

C. Membuat Garis Kontinum

| STS | TS | N |S |SS |




$$
\begin{array}{ll|l|l|l|l} 
& & & & & \\
65 & 117 & 169 & 221 & 273 & 325
\end{array}
$$

Sedangkan untuk menentukan nilai variabel yang akan dianalisis menggunakan nilai rata-rata atau mean (Sugiyono, 2014 dalam Utami, 2019:25). Data statistik penelitian diolah menggunakan aplikasi IBM SPSS versi 23 dengan Uji Validitas Pearson (menyatakan hasil data penelitian dalam kuisioner penelitian bersifat valid) dan Uji Realibilitas Alpha Cronbach (menyatakan kuisioner sebagai instrumen penelitian untuk menghimpun data bersifat reliabel atau konsisten).

\section{HASIL DAN PEMBAHASAN Gambaran Umum Kecak Fire Dance Uluwatu}

Tari Kecak adalah seni pertunjukan tradisional khas kebudayaan Bali yang menampilkan perpaduan antara nyanyian dan tarian. Spies dan Goris (1937: 67 dalam Erawati, 2019:3) mengemukakan awal terbentuknya Tari Kecak merupakan paduan suara laki-laki yang khusus diciptakan untuk mengiringi Tari Sanghyang bersifat magis dan sakral yang dipentaskan pada saat upacara pengusiran wabah penyakit. Kemudian tarian ini dikomodifikasi pada tahun 1930-an oleh seniman asal Bali I Wayan Limbak dan seniman asal Jerman Walter Spies memasukkan kisah Epos Ramayana dalam pertunjukan dan menambahkan penari karakter seperti Rama, Dewi Sinta, Rahwana, Hanoman, dan Sugriwa (Bandem, 1983: 41 dalam Kencana dkk., 2020:59).

Kecak Fire Dance Uluwatu atau Tari Kecak Uluwatu dipentaskan setiap hari Senin sampai Minggu mulai pukul 18:00 - 19:00, berlokasi di teater outdoor DTW Kawasan Luar Pura Uluwatu. Pertunjukan ini disajikan di atas tebing dengan pemandangan yang langsung mengarah ke laut, fasilitas tempat duduk memuat kapasitas sekitar 1.300 orang. Tiket pertunjukan dapat dibeli seharga Rp 150.000,00 per orang di loket depan pintu masuk teater maupun secara online (https://kumparan.com/). Menurut Ketua Sanggar Tari Dan Tabuh Karang Boma Desa Adat Pecatu, I Made Astra (Darmawan dkk., 2020:69), Kecak Fire Dance Uluwatu setiap hari mampu menampung 2.500 sampai 3.000 pengunjung domestik maupun manca negara per $1 \mathrm{x}$ pertunjukan.

Ada pun keistimewaan pertunjukan Kecak Fire Dance Uluwatu dari pertunjukan Tari Kecak di daerah lain adalah: 1) Pertunjukan ini dilangsungkan dengan panorama matahari terbenam (sunset) dari atas tebing; 2) Selama pertunjukan berlangsung, penari menyelipkan gurauan dan candaan untuk menghibur pengunjung agar tidak cepat bosan; dan 3) Menampilkan salah satu babak pertunjukan laga "Hanoman berperang melawan pasukan Rahwana", dimana penari
Hanoman melakukan aksi bermain dengan api (juga dikenal dengan sebutan "The Monkey Dance"). Selain itu, pengemasan kesenian Kecak Fire Dance Uluwatu ke dalam sektor pariwisata tidak meninggalkan identitas asli dari esensi kebudayaan Tari Kecak itu sendiri. Dengan demikian, Kecak Fire Dance Uluwatu sangat sesuai untuk dijadikan sebagai atraksi wisata entertainment yang berpotensi memperluas promosi dan eksistensinya melalui peran agen tour and travel yang memasukkan pertunjukan ini ke dalam preferensi produk paket wisata.

\subsection{Karakteristik Pengunjung Domestik yang Menyaksikan Wisata Entertainment di DTW Kawasan Luar Pura Uluwatu}

\section{Jenis Kelamin}

Berdasarkan hasil kuisioner penelitian dari 65 pengunjung domestik yang dijadikan sebagai responden, dapat diketahui bahwa pengunjung domestik menyaksikan Kecak Fire Dance Uluwatu berdasarkan jenis kelamin didominasi oleh pengunjung perempuan sebanyak 39 responden, sedangkan pengunjung laki-laki sebanyak 26 responden.

\section{Usia}

Berdasarkan hasil kuisioner penelitian dari 65 pengunjung domestik yang dijadikan sebagai responden, dapat diketahui bahwa pengunjung domestik menyaksikan Kecak Fire Dance Uluwatu berdasarkan usia adalah pengunjung berusia 0 - 14 tahun sebanyak 3 responden; pengunjung berusia 15 - 24 tahun sebanyak 35 respoden; pengunjung berusia 25 - 44 tahun sebanyak 26 responden; pengunjung berusia 45 - 65 tahun sebanyak 11 responden; dan pengunjung berusia lebih dari 65 tahun sebanyak 0 responden atau tidak ada.

\section{Pendidikan Terakhir}

Berdasarkan hasil kuisioner penelitian dari 65 pengunjung domestik yang dijadikan sebagai responden, dapat diketahui bahwa pengunjung domestik menyaksikan Kecak Fire Dance Uluwatu berdasarkan tingkat pendidikan terakhir adalah pengunjung Tidak Tamat SD dan lulusan Sekolah Dasar (SD) 0 responden atau tidak ada; pengunjung lulusan Sekolah Menengah Pertama (SMP) sebanyak 9 responden; pengunjung lulusan Sekolah Menengah Atas (SMA) sebanyak 22 responden; pengunjung lulusan Diploma/ Sarjana (S1) sebanyak 31 responden; pengunjung lulusan Magister (S2) sebanyak 2 responden; dan pengunjung lulusan Doktoral (S3) sebanyak 1 responden.

\section{Pekerjaan}

Berdasarkan hasil kuisioner penelitian dari 
65 pengunjung domestik yang dijadikan sebagai responden, dapat diketahui bahwa pengunjung domestik menyaksikan Kecak Fire Dance Uluwatu berdasarkan jenis pekerjaan adalah pengunjung berprofesi Pelajar/ Mahasiswa sebanyak 35 responden; pengunjung berprofesi PNS/ Pegawai Swasta sebanyak 11 responden; pengunjung berprofesi Wisaswasta sebanyak 8 responden; pengunjung berprofesi Ibu Rumah Tangga sebanyak 5 responden; pengunjung berprofesi Profesional dan Lainnya masing-masing berjumlah sama sebanyak 3 responden.

\section{Jumlah Anggota Keluarga dan Komposisinya}

Berdasarkan hasil kuisioner penelitian dari 65 pengunjung domestik yang dijadikan sebagai responden, dapat diketahui bahwa pengunjung domestik menyaksikan Kecak Fire Dance Uluwatu berdasarkan jumlah anggota keluarga dan komposisinya adalah pengunjung dengan beberapa orang tanpa anak usia dibawah 17 tahun sebanyak 26 responden; pengunjung dengan beberapa orang dengan anak (beberapa anak) dibawah 17 tahun sebanyak 22 responden; dan pengunjung dengan tidak ada anggota keluarga atau 1 orang (individu) sebanyak 17 responden.

\section{Tipe Keluarga}

Berdasarkan hasil kuisioner penelitian dari 65 pengunjung domestik yang dijadikan sebagai responden, dapat diketahui bahwa pengunjung domestik menyaksikan Kecak Fire Dance Uluwatu berdasarkan tipe keluarga adalah: Pengunjung yang Belum Menikah sebanyak 26 responden; Pengunjung yang Menikah, Anak Usia 6 - 17 tahun sebanyak 16 responden; Pengunjung yang Menikah, Anak Usia 18 - 25 tahun sebanyak 8 responden; Pengunjung yang Menikah, Belum Punya Anak dan Menikah, Anak Usia < 6 tahun masing-masing berjumlah sama sebanyak 6 responden; Pengunjung yang Menikah, Anak Usia > 25 tahun, Tidak tinggal dengan orang tua sebanyak 2 responden; dan Pengunjung yang Menikah, Anak Usia $>25$ tahun, Masih tinggal dengan orang tua sebanyak 1 responden.

\subsection{Persepsi Pengunjung Domestik Terhadap} Wisata Entertainment di DTW Kawasan Luar Pura Uluwatu

\section{A. Persepsi Pengunjung Domestik Terhadap Wisata Entertainment Berbasis Dimensi Learning}

Tabel 1 menunjukkan penilaian persepsi dari 65 responden mengenai Kecak Fire Dance Uluwatu berbasis Dimensi Learning, sehingga dapat diambil indikator tertinggi berdasarkan nilai ratarata tertinggi yang akan dijabarkan dalam Tabel 1.

*Warna kuning menunjukan nilai rata-rata tertinggi indikator Learning.

\section{Tabel 1. Persepsi Pengunjung Domestik Terhadap Wisata Entertainment Berbasis Dimensi Learning}

\begin{tabular}{|c|c|c|}
\hline No. & Indikator Learning & $\begin{array}{l}\text { Nilai } \\
\text { Rata- } \\
\text { rata }\end{array}$ \\
\hline 1. & $\begin{array}{l}\text { Saya berusaha memperluas } \\
\text { pemahaman saya mengenai } \\
\text { Tari Kecak (melalui Kecak Fire } \\
\text { Dance Uluwatu). }\end{array}$ & 4,20 \\
\hline 2. & $\begin{array}{l}\text { Saya memperoleh informasi } \\
\text { dan pengetahuan tentang Tari } \\
\text { Kecak (melalui Kecak Fire } \\
\text { Dance Uluwatu). }\end{array}$ & 4,09 \\
\hline 3. & $\begin{array}{l}\text { Saya belajar banyak hal tentang } \\
\text { Tari Kecak (melalui Kecak Fire } \\
\text { Dance Uluwatu). }\end{array}$ & 4,06 \\
\hline 4. & Saya belajar budaya baru. & 4,35 \\
\hline \multicolumn{3}{|c|}{$\begin{array}{l}\text { Nilai rata - rata persepsi pengunjung } \\
\text { domestik (berdasarkan rata-rata pembobotan } \\
\text { frekuensi) terhadap wisata entertainment pada } \\
\text { dimensi Learning yaitu } 277,5 \text { dan termasuk dalam } \\
\text { kategori sangat setuju. Sedangkan indikator } \\
\text { tertinggi dari dimensi Learning berdasarkan } \\
\text { perhitungan bobot frekuensi terletak pada indikator } \\
\text { "Saya belajar banyak hal tentang Tari Kecak (melalui } \\
\text { Kecak Fire Dance Uluwatu)". }\end{array}$} \\
\hline
\end{tabular}

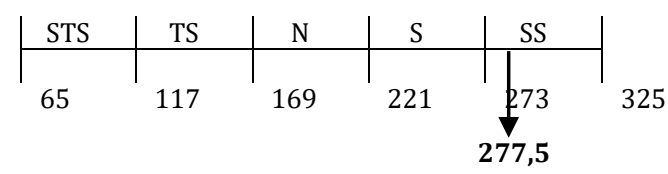

Indikator "Saya belajar banyak hal tentang Tari Kecak (melalui Kecak Fire Dance Uluwatu)" mendapat poin tertinggi dikarenakan selain menyuguhkan spirit kesakralan, Kecak Fire Dance Uluwatu mengandung pesan moral yang dibagikan kepada penonton melalui kisah pewayangan Epos Ramayana, antara lain: nilai kesetiaan (bakti Dewi Sinta kepada Shri Rama), nilai rela berkorban (Hanoman), dan tidak memiliki perangai yang buruk seperti Rahwana. Selain itu, Kecak Fire Dance Uluwatu juga merupakan wujud inovasi terhadap upaya rejuvinasi kebudayaan Hindu.

\section{B. Persepsi Pengunjung Domestik Terhadap Wisata Entertainment Berbasis Dimensi Enjoyment}

Tabel 2 menunjukkan penilaian persepsi dari 65 responden mengenai Kecak Fire Dance Uluwatu berbasis Dimensi Enjoyment, sehingga dapat diambil indikator tertinggi berdasarkan nilai rata-rata tertinggi yang akan dijabarkan dalam Tabel 2 . 
*Warna kuning menunjukan nilai rata-rata tertinggi indikator Enjoyment.

\section{Tabel 2. Persepsi Pengunjung Domestik Terhadap Wisata Entertainment Berbasis Dimensi Enjoyment}

\begin{tabular}{|c|c|c|}
\hline No. & Indikator Enjoyment & $\begin{array}{l}\text { Nilai } \\
\text { Rata- } \\
\text { rata }\end{array}$ \\
\hline 1. & Saya bersenang-senang. & 4,52 \\
\hline 2. & $\begin{array}{l}\text { Saya menikmati momen saya } \\
\text { selama menyaksikan } \\
\text { pertunjukan Kecak Fire } \\
\text { Dance Uluwatu. }\end{array}$ & 4,55 \\
\hline 3. & $\begin{array}{l}\text { Saya merasa senang } \mathrm{di} \\
\text { perjalanan saat menuju ke } \\
\text { lokasi pertunjukan Kecak Fire } \\
\text { Dance Uluwatu. }\end{array}$ & 4,16 \\
\hline 4. & $\begin{array}{l}\text { Pertunjukan Kecak Fire Dance } \\
\text { Uluwatu memotivasi saya } \\
\text { untuk melakukan perjalanan } \\
\text { wisata ke DTW Kawasan Luar } \\
\text { Pura Uluwatu. }\end{array}$ & 4,29 \\
\hline
\end{tabular}

Nilai rata - rata persepsi pengunjung domestik (berdasarkan rata-rata pembobotan frekuensi) terhadap wisata entertainment pada dimensi Enjoyment yaitu 285 dan termasuk dalam kategori sangat setuju. Sedangkan indikator tertinggi dari dimensi Enjoyment berdasarkan perhitungan bobot frekuensi terletak pada indikator "Saya menikmati momen saya selama menyaksikan pertunjukan Kecak Fire Dance Uluwatu".

\begin{tabular}{|l|c|c|c|c|c} 
STS & TS & N & S & SS & \\
\cline { 1 - 5 } 65 & 117 & 169 & 221 & $\underset{2 f 3}{2}$ & 325 \\
& & & & & \\
& & & & &
\end{tabular}

Indikator "Saya menikmati momen saya selama menyaksikan pertunjukan Kecak Fire Dance Uluwatu" mendapat poin tertinggi dikarenakan pertunjukan Kecak Fire Dance Uluwatu memiliki unique selling point berupa pementasan di atas ujung tebing berketinggian $90 \mathrm{mdpl}$, sehingga pengunjung merasa rileks dan lebih menikmati pertunjukan didukung panorama sunset yang menawan bertemu dengan garis cakrawala (Kencana dkk., 2020:61).

\section{Persepsi Pengunjung Domestik Terhadap Wisata Entertainment Berbasis Dimensi Escape}

Tabel 3 menunjukkan penilaian persepsi dari 65 responden mengenai Kecak Fire Dance Uluwatu berbasis Dimensi Escape, sehingga dapat diambil indikator tertinggi berdasarkan nilai rata-rata tertinggi yang akan dibajarkan dalam Tabel 3.
*Warna kuning menunjukan nilai rata-rata tertinggi indikator Escape.

\section{Tabel 3. Persepsi Pengunjung Domestik Terhadap Wisata Entertainment Berbasis Dimensi Escape}

\begin{tabular}{clc}
\hline No. & \multicolumn{1}{c}{ Indikator Escape } & $\begin{array}{c}\text { Nilai } \\
\text { Rata- } \\
\text { rata }\end{array}$ \\
\hline 1. & $\begin{array}{l}\text { Saya merasakan seperti berada } \\
\text { di dimensi lain. }\end{array}$ & 3,60 \\
\hline & $\begin{array}{l}\text { Saya merasa lepas dari } \\
\text { segala urusan kehidupan } \\
\text { sehari-hari. }\end{array}$ & $\mathbf{3 , 7 2}$ \\
\hline & $\begin{array}{l}\text { Saya terlalu menikmati } \\
\text { pertunjukan Kecak Fire Dance }\end{array}$ & \\
\hline & $\begin{array}{l}\text { Uluwatu sehingga melupakan } \\
\text { hal-hal di sekeliling saya. }\end{array}$ & \\
\hline & $\begin{array}{l}\text { Saya melakukan sesuatu yang } \\
\text { bermakna (melalui } \\
\text { menyaksikan pertunjukan } \\
\text { Kecak Fire Dance Uluwatu). }\end{array}$ \\
\hline
\end{tabular}

Nilai rata - rata persepsi pengunjung domestik (berdasarkan rata-rata pembobotan frekuensi) terhadap wisata entertainment pada dimensi Escape yaitu 227 dan termasuk dalam kategori setuju. Sedangkan indikator tertinggi dari dimensi Escape berdasarkan perhitungan bobot frekuensi terletak pada indikator "Saya merasa lepas dari segala urusan di kehidupan sehari-hari".

\begin{tabular}{|c|c|c|c|c|c} 
STS & TS & N & S & SS & \\
\cline { 1 - 4 } 65 & 117 & 169 & $\underset{2}{227}$ & 273 & 325 \\
& & & &
\end{tabular}

Indikator "Saya merasa lepas dari segala urusan di kehidupan sehari-hari" mendapat poin tertinggi dikarenakan pertunjukan Kecak Fire Dance Uluwatu mampu menggaet pengunjung domestik yang rela membeli tiket secara online dari jauh-jauh hari maupun duduk berhimpithimpitan dengan pengunjung lain karena kapasitas tempat duduk sudah melebihi batas. Hal ini dikemukakan dalam salah satu komentar dari Khofifah, pengunjung asal Bandung pada bulan November 2019 (https://www.tripadvisor.com/):

\footnotetext{
"Untuk yang tidak menyukai seni mungkin pertunjukan ini sedikit membosankan. Apalagi dengan banyaknya penonton. Saya menonton pertunjukan ini sore hari yang aslinya adalah pertunjukan favorite dan sulit sekali mendapat tiketnya. Tapi saya suka seni dan dengan menonton pertunjukan ini semua terbayarkan $($.".
}

D. Persepsi Pengunjung Domestik Terhadap Wisata Entertainment Berbasis Dimensi Refreshment

Tabel 4 menunjukkan penilaian persepsi dari 65 responden mengenai Kecak Fire Dance 
Uluwatu berbasis Dimensi Refreshment, sehingga dapat diambil indikator tertinggi berdasarkan nilai rata-rata tertinggi yang akan dijabarkan dalam Tabel 4.

*Warna kuning menunjukan nilai rata-rata tertinggi indikator Refreshment.

Tabel 4. Persepsi Pengunjung Domestik Terhadap Wisata Entertainment Berbasis Dimensi Refreshment

\begin{tabular}{lll}
\hline No. & Indikator Refreshment & $\begin{array}{c}\text { Nilai } \\
\text { Rata- } \\
\text { rata }\end{array}$ \\
\hline & $\begin{array}{l}\text { Saya merasa terbebaskan } \\
\text { dalam aspek psikis (mental) } \\
\text { ketika menikmati pertunjukan }\end{array}$ & 3,76 \\
$\begin{array}{l}\text { Kecak Fire Dance Uluwatu. } \\
\text { 2. }\end{array}$ & $\begin{array}{l}\text { Saya merasa disegarkan } \\
\text { kembali. }\end{array}$ & $\mathbf{3 , 8 7}$ \\
\hline
\end{tabular}

Nilai rata - rata persepsi pengunjung domestik (berdasarkan rata-rata pembobotan frekuensi) terhadap wisata entertainment pada dimensi Refreshment yaitu 248,5 dan termasuk dalam kategori setuju. Sedangkan indikator tertinggi dari dimensi Refreshment berdasarkan perhitungan bobot frekuensi terletak pada indikator "Saya merasa disegarkan kembali".

\begin{tabular}{|c|c|c|c|c|}
\hline STS & TS & $\mathrm{N}$ & $S$ & SS \\
\hline 65 & 117 & 169 & 221 & 273 \\
\hline
\end{tabular}

Indikator "Saya merasa disegarkan kembali" mendapat poin tertinggi dikarenakan sebagian besar pengunjung domestik yang mengunjungi DTW Kawasan Pura Luhur Uluwatu berasal dari provinsi lain, sehingga menjadi momen refleksi untuk mengevaluasi kembali diri-sendiri dan cara pandang terhadap lingkungan sosial-budaya di daerah asal (Cohen, 1979 dalam Luo dan kawan-kawan, 2018:5).

\section{E. Persepsi Pengunjung Domestik Terhadap Wisata Entertainment Berbasis Dimensi Novelty}

Tabel 5 menunjukkan penilaian persepsi dari 65 responden mengenai Kecak Fire Dance Uluwatu berbasis Dimensi Novelty, sehingga dapat diambil indikator tertinggi berdasarkan nilai rata-rata tertinggi yang akan dijabarkan dalam Tabel 5.

*Warna kuning menunjukan nilai rata-rata tertinggi indikator Novelty.

Tabel 5. Persepsi Pengunjung Domestik Terhadap Wisata Entertainment Berbasis Dimensi Novelty

\begin{tabular}{llc}
\hline No. & \multicolumn{1}{c}{ Indikator Novelty } & $\begin{array}{c}\text { Nilai } \\
\text { Rata- } \\
\text { rata }\end{array}$ \\
\hline & $\begin{array}{l}\text { Menurut saya, menyaksikan } \\
\text { pertunjukan Kecak Fire Dance }\end{array}$ & 3,52 \\
Uluwatu adalah pengalaman \\
sekali seumur hidup.
\end{tabular}

Nilai rata - rata persepsi pengunjung domestik (berdasarkan rata-rata pembobotan frekuensi) terhadap wisata entertainment pada dimensi Novelty yaitu 259,25 dan termasuk dalam kategori setuju. Sedangkan indikator tertinggi dari dimensi Novelty berdasarkan perhitungan bobot frekuensi terletak pada indikator "Saya merasa pertunjukan Kecak Fire Dance Uluwatu itu unik." .

\begin{tabular}{|c|c|c|c|c|}
\hline STS & TS & $\mathrm{N}$ & S & SS \\
\hline 65 & 117 & 169 & 221 & 273 \\
\hline
\end{tabular}

Indikator "Saya merasa pertunjukan Kecak Fire Dance Uluwatu itu unik" mendapat poin tertinggi dikarenakan wujud Tari Kecak tidak mengandalkan suara alat musik, melainkan perpaduan lantunan suara para penari yang mengiringi penampilan. Selain itu, penambahan cerita Epos Ramayana dan adegan epik Hanoman yang bermain dengan properti api dijadikan sebagai daya tarik dalam strategi pemasaran paket wisata khusus Kecak Fire Dance Uluwatu kepada pengunjung (Darmawan dkk., 2020: 69).

\section{F. Persepsi Pengunjung Domestik Terhadap Wisata Entertainment Berbasis Dimensi Involvement}

Tabel 6 menunjukkan penilaian persepsi dari 65 responden mengenai Kecak Fire Dance Uluwatu berbasis Dimensi Involvement, sehingga dapat diambil indikator tertinggi berdasarkan nilai rata-rata tertinggi yang akan dijabarkan dalam Tabel 6.

*Warna kuning menunjukan nilai rata-rata tertinggi indikator Involvement.

Tabel 6. Persepsi Pengunjung Domestik Terhadap Wisata Entertainment Berbasis Dimensi Involvement

No. Indikator Involvement Nilai




\begin{tabular}{llc}
\hline & & \multicolumn{1}{c}{$\begin{array}{c}\text { Rata- } \\
\text { rata }\end{array}$} \\
\hline & $\begin{array}{l}\text { Saya mengunjungi DTW } \\
\text { Kawasan Luar Pura Uluwatu } \\
\text { sebagai destinasi yang benar- } \\
\text { benar ingin kunjungi selama di } \\
\text { Bali. }\end{array}$ & 3,87 \\
\hline & $\begin{array}{l}\text { Saya menikmati pertunjukan } \\
\text { yang ingin disaksikan di } \\
\text { DTw Kawasan Luar Pura }\end{array}$ & \\
\hline & $\mathbf{4 , 2 3}$ \\
\hline Uluwatu. & $\begin{array}{l}\text { Saya tertarik pada pertunjukan } \\
\text { yang disediakan di DTW } \\
\text { Kawasan Luar Pura Uluwatu. }\end{array}$ & 4,16 \\
\hline
\end{tabular}

Nilai rata - rata persepsi pengunjung domestik (berdasarkan rata-rata pembobotan frekuensi) terhadap wisata entertainment pada dimensi Involvement yaitu 266 dan termasuk dalam kategori setuju. Sedangkan indikator tertinggi dari dimensi Involvement berdasarkan perhitungan bobot frekuensi terletak pada indikator "Saya menikmati pertunjukan yang ingin disaksikan di DTW Kawasan Luar Pura Uluwatu".

\begin{tabular}{|c|c|c|c|c|c} 
STS & TS & N & S & SS & \\
\cline { 1 - 4 } 65 & 117 & 169 & $221{\underset{\mathbf{2 6 6}}{273}}_{325}^{273}$ &
\end{tabular}

Indikator "Saya menikmati pertunjukan yang ingin disaksikan di DTW Kawasan Luar Pura Uluwatu" mendapat poin tertinggi dikarenakan pihak pengelola membangun fasilitas dan layanan pariwisata untuk memenuhi kebutuhan pengunjung, tempat parkir yang luas, toko-toko cinderamata, dan pertunjukan Kecak Fire Dance Uluwatu itu sendiri sebagai bagian dari hiburan yang disediakan pengelola (Kencana dkk., 2020:58).

\section{G. Persepsi Pengunjung Domestik Terhadap Wisata Entertainment Berbasis Dimensi Local Culture}

Tabel 7 menunjukkan penilaian persepsi dari 65 responden mengenai Kecak Fire Dance Uluwatu berbasis Dimensi Local Culture, sehingga dapat diambil indikator tertinggi berdasarkan nilai rata-rata tertinggi yang akan dijabarkan dalam Tabel 7.

*Warna kuning menunjukan nilai rata-rata tertinggi indikator Local Culture.

\section{Tabel 7. Persepsi Pengunjung Domestik Terhadap Wisata Entertainment Berbasis Dimensi Local Culture}

No. Indikator Local Culture $\begin{gathered}\text { Nilai } \\ \text { Rata- } \\ \text { rata }\end{gathered}$

\begin{tabular}{lll}
\hline 1. Saya memiliki kesan yang & \multicolumn{1}{l}{$\begin{array}{l}\text { baik tentang masyarakat } \\
\text { lokal. }\end{array}$} & $\mathbf{4 , 3 6}$ \\
\hline 2. & $\begin{array}{l}\text { Saya mengalami ikatan erat } \\
\text { dengan budaya lokal. }\end{array}$ & 4,00 \\
\hline 3. & $\begin{array}{l}\text { Saya merasa masyarakat lokal } \\
\text { di DTW Kawasan Luar Pura }\end{array}$ & 4,20 \\
& Uluwatu sangat ramah. \\
\hline
\end{tabular}

domestik rata - rata persepsi pengunjung frekuensi) terhadap wisata entertainment pada dimensi Local Culture yaitu 272,3 dan termasuk dalam kategori sangat setuju. Sedangkan indikator tertinggi dari dimensi Local Culture berdasarkan perhitungan bobot frekuensi terletak pada indikator "Saya memiliki kesan yang baik tentang masyarakat lokal".

\begin{tabular}{|l|l|l|l||l|l} 
STS & TS & N & S & SS & \\
\cline { 3 - 5 } 65 & 117 & 169 & 221 & \multirow{2}{272,3}{} & \\
& & & & &
\end{tabular}

Indikator "Saya memiliki kesan yang baik tentang masyarakat lokal" mendapat poin tertinggi dikarenakan pengelolaan terintegrasi di DTW Kawasan Luar Pura Uluwatu yang melibatkan berbagai stakeholders seperti Desa Pakraman Pecatu, Pemerintah Desa Pecatu, Pemerintah Kabupaten Badung, serta Pihak Keluarga Jro Puri Kuta, dan Keluarga Puri Celagi Gedog Denpasar (Yudasuara, 2015:135-137). Dengan demikian, pengelolaan Obyek Wisata Kawasan Luar Pura Uluwatu menjadi bersih, rapih, dan taat dengan aturan.

Berdasarkan penelitian yang dilakukan oleh Yudasuara (2015:135-137), aktor-aktor pemangku kepentingan yang terlibat dalam pengelolaan DTW Kawasan Luar Pura Uluwatu beserta perannya:

\section{Desa Pakraman Pecatu}

Desa Pakraman Pecatu berperan sebagai pengelola utama yang bertanggung jawab dalam pemeliharaan, pelestarian, penataan, keamanan dan hak melakukan pungutan retribusi masuk bagi pengunjung.

\section{Pemerintah Desa Pecatu}

Pemerintah Desa Pecatu bekerja sama dengan Lembaga Desa Pakraman Pecatu berperan untuk memberdayakan masyarakat lokal (Warga Desa Pakraman Pecatu) yang dipekerjakan sebagai petugas pengelolaan. Petugas pengelola mendapatkan pembinaan dan pelatihan di bidang tour guiding seperti kursus bahasa asing, teknik pemandu wisata, wawasan adat dan budaya serta sistem pengelolaan DTW.

\section{Pemerintah Kabupaten Badung}

Pemerintah Kabupaten Badung bertugas sebagai penanggung jawab kewilayahan, fasilitator pembangunan fisik dan non-fisik, pembina serta pengawas pengelolaan. 


\section{Pihak Keluarga Jro Puri Kuta, dan Keluarga Puri Celagi Gedog Denpasar}

Kedua stakeholder diatas bertugas sebagai pengempon yang berperan pada pelaksanaan upacara keagamaan.

Oleh karena itu, perbandingan peringkat rata-rata nilai persepsi pengunjung domestik terhadap Kecak Fire Dance Uluwatu berdasarkan dimensi Wisata Entertainment dapat disusun seperti Tabel 8:

Tabel 8. Peringkat Rata-rata Nilai

Persepsi Berdasarkan Dimensi-dimensi Wisata Entertainment

Persepsi Pengunjung Domestik terhadap Wisata Entertainment di DTW Kawasan Luar Pura Uluwatu

\begin{tabular}{|c|c|c|}
\hline $\begin{array}{c}\text { Peringkat } \\
\text { (Nilai } \\
\text { Tertinggi) }\end{array}$ & Dimensi & $\begin{array}{c}\text { Rata-rata } \\
\text { Nilai }\end{array}$ \\
\hline 1 & Enjoyment & 285 \\
\hline 2 & Learning & 277,5 \\
\hline 3 & Local Culture & 272,33 \\
\hline 4 & Involvement & 266 \\
\hline 5 & Novelty & 259,25 \\
\hline 6 & Refreshment & 248,5 \\
\hline 7 & Escape & 227 \\
\hline
\end{tabular}

\section{KESIMPULAN}

Karakteristik pengunjung domestik yang menyaksikan wisata entertainment (Kecak Fire Dance Uluwatu) di DTW Kawasan Luar Pura Uluwatu dengan jumlah sampel sebanyak 65 respoden didominasi pengunjung dengan kriteria: a. Jenis kelamin Perempuan (39 responden); b. Berusia 15 - 24 tahun (35 responden); c. Pendidikan terakhir Diploma/ Sarjana (S1) (31 responden); d. Berprofesi Pelajar/ Mahasiswa (35 responden); e. Beberapa orang tanpa anak usia dibawah 17 tahun (26 responden); dan f. Belum Menikah (26 responden). Persepsi pengunjung domestik terhadap wisata entertainment (Kecak Fire Dance Uluwatu) di DTW Kawasan Luar Pura Uluwatu dari total sampel (pengunjung domestik) 65 responden memberikan nilai sangat setuju pada dimensi Learning $(277,5)$ dan Enjoyment (285). Sedangkan nilai setuju diberikan pada dimensi Escape (227), Refreshment $(248,5)$, Novelty $(259,25)$, Involvement (266), dan Local Culture $(272,33)$. Indikator masingmasing dimensi wisata entertainment yang memiliki hasil pembobotan frekuensi tertinggi yang akan dijabarkan di Tabel 9.

\section{Tabel 9. Simpulan Indikator Dimensi Wisata Entertainment Berbasis Hasil Pembobotan Frekuensi}

\begin{tabular}{|l|l|l|} 
Sub-variabel & Indikator & Hasil
\end{tabular}

\begin{tabular}{|c|c|c|}
\hline $\begin{array}{c}\text { (Dimensi } \\
\text { Wisata } \\
\text { Entertainment) }\end{array}$ & & $\begin{array}{l}\text { Pembobotan } \\
\text { Frekuensi }\end{array}$ \\
\hline Learning & $\begin{array}{l}\text { Saya belajar } \\
\text { banyak hal } \\
\text { tentang Tari } \\
\text { Kecak (melalui } \\
\text { Kecak Fire } \\
\text { Dance } \\
\text { Uluwatu). }\end{array}$ & 288 \\
\hline Enjoyment & $\begin{array}{l}\text { Saya } \\
\text { menikmati } \\
\text { momen saya } \\
\text { selama } \\
\text { menyaksikan } \\
\text { pertunjukan } \\
\text { Kecak Fire } \\
\text { Dance Uluwatu }\end{array}$ & 296 \\
\hline Escape & $\begin{array}{lr}\text { Saya merasa } \\
\text { lepas dari } \\
\text { segala urusan } \\
\text { di kehidupan } \\
\text { sehari-hari }\end{array}$ & 237 \\
\hline Refreshment & $\begin{array}{l}\text { Saya merasa } \\
\text { disegarkan } \\
\text { kembali }\end{array}$ & 252 \\
\hline Novelty & $\begin{array}{l}\text { Saya merasa } \\
\text { pertunjukan } \\
\text { Kecak Fire } \\
\text { Dance Uluwatu } \\
\text { itu unik }\end{array}$ & 287 \\
\hline Involvement & $\begin{array}{l}\text { Saya } \\
\text { menikmati } \\
\text { pertunjukan } \\
\text { yang ingin } \\
\text { disaksikan di } \\
\text { DTW Kawasan } \\
\text { Luar Pura } \\
\text { Uluwatu }\end{array}$ & 275 \\
\hline Local Culture & $\begin{array}{lr}\text { Saya } & \text { memiliki } \\
\text { kesan } & \text { yang } \\
\text { baik } & \text { tentang } \\
\text { masyarakat } \\
\text { lokal }\end{array}$ & 284 \\
\hline
\end{tabular}

Tiga dimensi wisata entertainment yang memiliki nilai rata-rata teratas adalah dimensi Enjoyment (285), Learning $(277,5)$, dan Local Culture $(272,33)$.

Pengelola DTW Kawasan Luar Pura Uluwatu yang menekankan pada strategi-strategi yang dapat mempertahankan ketiga dimensi wisata entertainment dengan nilai rata-rata dominan yaitu Dimensi Enjoyment, pihak pengelola dapat melakukan pembenahan internal terhadap pengelolaan DTW Kawasa Luar Pura Uluwatu oleh pihak pengelola terkait pendataan, keamanan, dan kenyamanan penonton Kecak Fire Dance Uluwatu secara disiplin dan konsisten. Sedangkan pada 
Vol. 8 No 2, 2020

Dimensi Learning, pihak pengelola dapat memberikan edukasi kepada pengunjung sudah duduk di tribun teater mengenai latar belakang secara singkat mengenai Tari Kecak dan tema yang diangkat mengenai "Kisah Penyelamatan Dewi Shinta oleh Rama dari Tangan Rahwana" dalam Epos Ramayana sebelum pertunjukan dimulai. Selain itu, inovasi pembuatan $Q R$ Code khusus yang langsung tersambung ke website Tari Kecak Uluwatu menjadi strategi tepat untuk menyebarluaskan informasi sejarah mengenai Kecak Fire Dance Uluwatu. QR Code akan ditempelkan di loket tiket Obyek Wisata Pura Uluwatu dan pertunjukan Kecak Fire Dance Uluwatu dan papan pengumuman yang tersebar di beberapa lokasi dalam obyek wisata. Serta pada Dimensi Local Culture, pihak pengelola dapat membuat sesi interaksi dengan pengunjung berupa pelibatan pengunjung untuk ikut menari bersama mengikuti gerakan penari-penari Tari Kecak maupun para penari tokoh Ramayana pada saat pertunjukan berlangsung.

\section{DAFTAR PUSTAKA}

Anonim. 2019. http://etheses.uin-malang.ac.id/ 712/7/10510074\%20Bab\%203.pdf, diakses pada tanggal 4 April 2020.

Anom, M. Par., Dr. Drs. I Putu dan Mahagangga, S.Sos., M.Si, I Gusti Agung Oka. 2019. Handbook Ilmu Pariwisata Karakter dan Prospek. Jakarta: Prenada Media (Divisi Kencana)

Anom, M. Par., Dr. Drs. I Putu dan Mahagangga, S.Sos., M.Si, I Gusti Agung Oka. 2019. 2020. Spektrum Ilmu Pariwisata Mitos Sebagai Modal Budaya Dalam Pengembangan Pariwisata Bali. Jakarta: Prenada Media (Divisi Kencana)

Darmawan, I. P. I., dkk. 2020. Kecak Touristic Performance in Uluwatu Temple: Its Aspects of Vocal Karawitan. Jurnal Bali Membangun Bali, 1(1), 65-72. http://103.110.185.64/index.php/jbmb/article/view/109

Dinas Pariwisata Provinsi Bali. 2018. Buku Analisis Pasar Wisatawan Nusantara Tahun 2018. https://disparda.baliprov.go.id/wpcontent/uploads/2019/11/Buku-Analisis-Pasar-WisatawanNusantara-2018-2.pdf, diakses pada tanggal 2 Maret 2020.

Erawati, N. M. P. 2019. Pariwisata Dan Budaya Kreatif: Sebuah Studi Tentang Tari Kecak Di Bali. Kalangwan: Jurnal Seni Pertunjukan, 5(1), 1-6. https://doi.org/10.31091/kalangwan.v5i1.731

Hughes, H. 2010. Arts, Entertainment and Tourism. Oxford: Taylor \& Francis.

Keliwar, S. \& Nurcahyo, A. 2015. Motivasi Dan Persepsi Pengunjung Terhadap Obyek Wisata Desa Budaya Pampang Di Samarinda. Jurnal Manajemen Resort Dan Leisure, 12(2). https://doi.org/10.17509/jurel.v12i2.1462

Kencana, I. P. A. P. dkk. 2020. Identity of Kecak Touristic Performance in Uluwatu Temple. Journal of Music Science, Technology, and Industry, 3(1), 57-62. https://jurnal.isidps.ac.id/index.php/jomsti/article/view/963

KumparanNEWS. 2020. https://kumparan.com/kumparannews/ cegah-penyebaran-corona-pertunjukan-tari-kecak-di-pura-

uluwatu-ditutup-1t3CbEngXpr/full, diakses pada tanggal 1 April 2020 .
Luo, J. M., dkk. 2018. The Development Of Measurement Scale For Entertainment Tourism Experience: A Case Study In Macau. Current Issues in Tourism, 1-15. https://doi.org/10.1080/ 13683500.2018.1556251

Luo, J. M., \& Lam, C. F. 2017. Entertainment Tourism. Oxon: Routledge.

Muhson, A. 2006. Teknik Analisis Kuantitatif. Yogyakarta: Universitas Negeri Yogyakarta.

Nurhidayah, N., \& Musadad, M. 2017. Karakteristik Pengunjung Pada Objek Wisata Danau Cipogas Kabupaten Rokan Hulu. Jurnal Online Mahasiswa Fakultas Ilmu Sosial dan Ilmu Politik Universitas Riau, vol. 4, no. 2, Oct. 2017, pp. 1-14.

Praing, Y. dkk. 2019. Karakteristik Dan Motivasi Kerja Karyawan Di Mahagiri Resort Nusa Lembongan (Laporan Penelitian Lapangan II). Denpasar: Program Studi D4 Pariwisata Fakultas Pariwisata Universitas Udayana.

Rai Utama, I.G.B. 2016. Teknik Sampling dan Penentuan Jumlah Sampel. DOI: 10.13140/RG.2.1.5187.0808. https://www.researchgate.net/publication/289657773, diakses pada tanggal 23 Maret 2020.

Seaton, A. V., \& Bennett, M. M. 1996. The Marketing Of Tourism Products: Concepts, Issues And Cases. United Kingdom: Thomson Learning.

Seriasih, W. 2019. Komodifikasi Tari Kecak Dalam Seni Pertunjukan Di Bali (Kajian Estetika Hindu). Jurnal Widya Sastra Pendidikan Agama Hindu, 2(1), 61-68. http://www.theartoftefl.org/index.php/WPAH/article/view/ 41

Setiawan, L. \& Suryasih, I.A. 2016. Karakteristik Dan Persepsi Wisatawan Terhadap Daya Tarik Wisata Pantai Kata Di Kota Pariaman, Sumatera Barat. Jurnal Destinasi Pariwisata, 4(1), 1 - 6. https://doi.org/10.24843/JDEPAR.2016.v04.i01.p01

Siregar, S. 2013. Metodologi Penelitian Kuantitatif dilengkapi dengan Perhitungan Manual dan SPSS. Jakarta: Kencana Media Group.

Sugiyono. 2012. Metode Penelitian Kuantitatif dan Kualitatif. Bandung: Alfabeta.

Suwena, I. K., dan Widyatmaja, I. G. N. 2017. Pengetahuan Dasar Ilmu Pariwisata. Denpasar: Udayana University Press.

Tripadvisor. 2020. https://www.tripadvisor.com/ Attraction_Review-g1380108-d3264822-ReviewsKecak_and_Fire_Dance-Pecatu_Nusa_Dua_Peninsula_Bali.html, diakses pada tanggal 13 Mei 2020.

United Nations. 2008. International Recommendations for Tourism Statistics 2008. https://unstats.un.org/unsd/publication/ Seriesm/SeriesM_83rev1e.pdf\#page=21, diakses pada tanggal 23 Maret 2020.

UNWTO. 2017. Glossary of Tourism Terms. https://unwto.org/ glossary-tourism-terms, diakses pada tanggal 23 Maret 2020.

Utami, N.K. 2019. Pengalaman Pengunjung Di Asia Afrika Festival 2019. Proyek Akhir. Bandung: Program Studi Manajemen Bisnis Kovensi \& Event Sekolah Tinggi Pariwisata Bandung.

Yudasuara, I. K. 2015. Pengelolaan Daya Tarik Wisata Berbasis Masyarakat Di Desa Pecatu, Kuta Selatan, Kabupaten Badung. Jurnal Master Pariwisata (JUMPA) Volume 2 Nomor 1, Juli 2015: 132 - 149. https://doi.org/10.24843/JUMPA.2015.v02. i01.p08 